\title{
A comparison of high-end methods for topographic modelling of a coastal dune complex
}

\author{
Chen Suo \\ Technological University Dublin, d15123973@mytudublin.ie \\ Eugene McGovern \\ Technological University Dublin, eugene.mcgovern@tudublin.ie \\ Alan Gilmer \\ Technological University Dublin, alan.gilmer@tudublin.ie
}

See next page for additional authors

Follow this and additional works at: https://arrow.tudublin.ie/beschrecart

Part of the Environmental Sciences Commons, and the Soil Science Commons

\section{Recommended Citation}

Suo, C., McGovern, E., Gilmer, A. et al. A comparison of high-end methods for topographic modelling of a coastal dune complex. J Coast Conserv 24, 47 (2020). DOI: 10.1007/s11852-020-00764-6

This Article is brought to you for free and open access by the School of Surveying and Construction Management at ARROW@TU Dublin. It has been accepted for inclusion in Articles by an authorized administrator of ARROW@TU Dublin. For more information, please contact arrow.admin@tudublin.ie, aisling.coyne@tudublin.ie, gerard.connolly@tudublin.ie.

Funder: Technological University Dublin

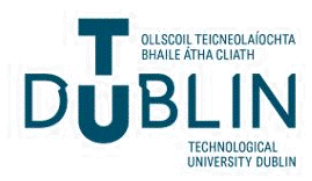


Authors

Chen Suo, Eugene McGovern, Alan Gilmer, and Conor Cahalane

This article is available at ARROW@TU Dublin: https://arrow.tudublin.ie/beschrecart/69 


\title{
A comparison of high-end methods for topographic modelling of a coastal dune complex
}

\author{
Chen Suo ${ }^{1}$ (D) $\cdot$ Eugene McGovern ${ }^{1} \cdot$ Alan Gilmer $^{2} \cdot$ Conor Cahalane $^{3}$ \\ Received: 1 May 2019 /Revised: 25 June 2020 / Accepted: 29 June 2020 / Published online: 18 July 2020 \\ (C) Springer Nature B.V. 2020
}

\begin{abstract}
In recent years, increasing tourism and development in the coastal dune area of the South East of Ireland have resulted in greater pressure on the environment, resulting in issues including soil erosion, flooding and habitat loss. Topographic mapping across a dune field is important for the development of targeted land management actions that maintain biodiversity and ecological functions. Developments in surveying technology, including LiDAR, terrestrial laser scanners (TLS) and aerial surveying from Remotely Piloted Aircraft Systems (RPAS), have enabled high-resolution and high-accuracy spatial data to be gathered quickly and relatively easily for 3D topographic modelling of a coastal dune complex. To-date, however, the relative efficacies of these three modelling methods, in the context of coastal dune modelling, has not been explored. This paper compares high-end methods based on LiDAR, TLS and RPAS technologies, for the topographic modelling of coastal dune complexes with particular reference to the Brittas-Buckroney dune complex in the South East of Ireland. The results identify the advantages and disadvantages of the respective technologies and highlight the efficacy of RPAS, in particular, for topographic modelling of coastal dune complexes. These results can provide reference information for others when selecting suitable methods for topographic modelling of similar environments.
\end{abstract}

Keywords Coastal dune complexes $\cdot$ Topographic modelling $\cdot$ LiDAR $\cdot$ Terrestrial laser scanners $\cdot$ Remotely piloted aircraft systems

\section{Introduction}

Coastal zones comprise $2 \%$ of the earth's land area and are the transition areas between the marine and terrestrial environments (Acosta et al. 2005). Dune complexes are the main

Chen Suo

d15123973@mytudublin.ie

Eugene McGovern

eugene.mcgovern@tudublin.ie

Alan Gilmer

alam.gilmer@tudublin.ie

Conor Cahalane

conor.cahalane@mu.ie

1 School of Surveying and Construction Management, Technological University Dublin, Dublin, Ireland

2 Environmental Sustainability \& Health Institute, Technological University Dublin, Dublin, Ireland

3 Department of Geography, Maynooth University Co., Maynooth, Kildare, Ireland structures at these coastal zones (Lucas et al. 2002). They play an essential role in the preservation of ecosystem stability and biological diversity as they provide habitat for special flora and fauna, control soil erosion and flooding, and provide protection for nearby properties from other environmental hazards (Clark 1977; Andrews et al. 2002). Human pressure on coastal zones around the world has increased dramatically in the last 50 years (Curr et al. 2000; Westley and McNeary 2014).

Concern for the increasing threat to coastal dune ecosystems has generated a greater interest in coastal dune conservation and management (MacLeod et al. 2002; Olbert et al. 2017). Accurate 'baseline' topographic mapping, with detailed information concerning the earth's surface, are considered critical to the development of an effective coastal environmental management plan (Acosta et al. 2005). However, high-resolution and high-accuracy topographic modelling is a challenging task which requires a considerable investment in time and resources (McKenna et al. 2005).

Aerial photogrammetry and optical satellite imagery have been used for topographic mapping for various landscapes including coastal ecosystems (Curr et al. 2000). However, a 
single dune complex is typically represented as a long and narrow strip because such mapping is generally produced at national and regional scales (Acosta et al. 2005). There are, notwithstanding, a number of data processing approaches for generating finer-scale mapping from the more traditional sources (Lucas et al. 2002; Timm and McGarigal 2012; Rapinel et al. 2014). Nevertheless, it remains quite difficult to produce, from these sources, topographic mapping with accurate and detailed land cover information for small coastal dune complexes. A considerable limitation of optical satellite imagery, in particular, is the influence of weather, especially cloud-cover which can interfere with the view of the earth's surface (McGovern et al. 2002).

Aircraft-based Light Detection and Ranging (LiDAR) is an alternative resource for 3D topographic models even for a smaller target area e.g. 50-100 ha (Bolivar et al. 1995; Grebby et al. 2014). It is often available from national mapping agencies (NMA's), such as Ordnance Survey Ireland (OSi). OSi quotes spatial resolutions and vertical accuracies in rural areas of $0.5 \mathrm{~m}$ and $0.5 \mathrm{~m}$ respectively (OSi 2017) and charges c. $€ 250$ per square kilometre for the data. LiDAR data can be used to generate both Digital Terrain Models (DTM) and Digital Surface Models (DSM) (Crapoulet et al. 2016). For a study at a coastal dune complex in North Carolina, a LiDAR dataset were used to represent coastal dunes for volumetric change analysis (Woolard and Colby 2002).

Ground surveying methods, including Total Station (TS) and Global Navigation Satellite System (GNSS), are suitable for topographic modelling of smaller target areas (D'iorio et al. 2007; Lee et al. 2013). These on-site, data collection methods provide more ground truth, and up-to-date and accurate information than many alternatives (D'iorio et al. 2007). The distance measurement accuracy of TS is $2 \mathrm{~mm}+2 \mathrm{ppm}$ over a distance of about $1 \mathrm{~km}$ (Lee et al. 2013). However, the operation and performance of TS in field surveying projects is limited by poor visibility circumstances, such as darkness, rain, snow, thickets or physical occlusions (Schneider and Panich 2008). There are three techniques based on GNSS to enhance the precision of satellite position data. These are Post Processing Kinematic (PPK), Real Time Kinematic (RTK) and Network Real Time Kinematic (NRTK) (Li et al. 2015). The accuracy of GNSS is 10-20 mm (Dow et al. 2009). With lighter equipment and easier operation, these GNSS techniques can save labour and time in collecting the same amount of modelling data as TS (Mieczysław 2013).

In recent years, due to being non-contact, rapid, accurate and complete, Terrestrial Laser Scanning (TLS) has been increasingly used to build three-dimensional models (Parrish et al. 2016). The positioning accuracy of TLS is of the order of millimetres (Staiger 2003). The laser scanner is integrated with a computing device to save the acquired point information and also to control the scanning patterns. The operation of the laser scanner is almost fully automatic which leaves little room for operating error as human influence plays a less important role in the surveying process (Ersilia et al. 2012).

Most recently, Remotely Piloted Aircraft Systems (RPAS), variously referred as Unmanned Aerial Systems (UAS), Unmanned Aerial Vehicles (UAV's), “Aerial Robots" or simply "drones", have enabled high-quality data to be gathered quickly and easily (Casella et al. 2014; Turner et al. 2016). RPAS platforms are typically grouped into two main categories: rotary RPAS and fixed-wing RPAS (Gomez and Green 2017). Comparing both types, rotary RPAS has more complex mechanics, which result in lower speeds and shorter flight ranges while fixed-wing RPAS have a simpler structure providing more stable platforms. Furthermore, fixed-wing RPAS enable longer flight duration and higher speeds, which are more suitable for aerial surveys over larger areas.

RPAS, integrated with modern digital camera technology, breaks the time and space constraint allowing a study site to be remotely surveyed in a significantly reduced time using the imagery acquired (Smith et al. 2009; Colomina and Molina 2014). RPAS imagery, using Structure from Motion (SfM) processing techniques, has created a new opportunity for photogrammetry to create 3D surface models from the large number of overlapping photographs (Hodgson et al. 2013). To maintain the spatial accuracy of the data, the overlapping area for each two images should be at least $60 \%$, making sure sufficient shared points can be recognised by the software for map construction (Zelizn 2016). A multispectral camera mounted on a RPAS allows both visible and multispectral imagery to be captured that can be used for characterizing land features, vegetation health and function (FernándezGuisuraga et al. 2018). RPAS is also a user-friendly and scalable methodology albeit with the requirement of specialized software and with restrictive image collection conditions such as high wind speed and poor light intensity (Bemis et al. 2014). For the management of RPAS, different countries have different mandatory requirements, established by their national aviation authorities. And particular operating licenses and insurances may be required before operating an RPAS (Tomasello et al. 2016).

LiDAR, TLS and RPAS technologies are capable of creating digital topographic models of coastal dune complexes. There are three different types of digital topographic model, viz. Digital Surface Model (DSM), Digital Terrain Model (DTM) and Digital Elevation Model (DEM). A DSM represents the natural and built features on the Earth's surface (Crapoulet et al. 2016). A DTM is defined as an array of orderly values that are used to describe the spatial distribution of various properties of the earth's surface, for example, topographic information, natural resource and environment information, and economic information (Liang et al. 2012).When the DTM is used only to describe and express spatial information, such as terrain relief and elevations, it is also called a DEM (Liang et al. 2012). A DTM is a bare-earth raster grid 
referenced to a vertical datum (Hutchinson and Gallant 1999). By filtering out non-ground points, e.g. building and vegetation cover in a DSM, a bare-earth DTM is created.

TLS and RPAS technologies create DSMs of a study site as the ground features are not filtered. LiDAR use pules of laser light to measure range. A single pulse can generate a number of returns such that the first return can be used to create a DSM and last return can be used to create a DTM.

The objective of this research was to compare three highend methods, viz. LiDAR, TLS and RPAS technology, for topographic modelling of a coastal dune complex with particular reference to the Brittas-Buckroney dune complex (Fig. 1) in Co. Wicklow, Ireland. By comparing the efficacy of these different methods of spatial data collection, with respect to accessibility, cost, convenience and data quality, the advantages and disadvantages of these methods are considered in the context of topographic modelling of coastal dune complexes. The results can provide reference information for others involved in topographic modelling of similar environments.

\section{Study site}

The Brittas-Buckroney dune complex (Fig. 2) is located c. $10 \mathrm{~km}$ south of Wicklow town on the east coast of Ireland and comprises two main sand dune systems, viz. Brittas Bay and Buckroney Dunes (National Parks and Wildlife Service (NPWS) 2013). The study site for this research is Buckroney Dunes. The area of the Buckroney dune complex is c. 60 ha.

Within this site, ten habitats listed on the EU Habitats Directive are present, including two priority habitats in
Ireland, viz. fixed dune and decalcified dune heath (National Parks and Wildlife Service (NPWS) 2013). This site also contains good examples of different dune types. At the northern part of Buckroney dune complex, there are some representative parabolic dunes, while embryonic dunes mostly occur at the southern part. Meanwhile, the site is notable for the presence of well-developed plant communities.

With land acquisition in recent years, the marginal areas of the dune system have been reclaimed as farmland. The increasing anthropogenic activities at the dune system, such as farming and recreation activities, have brought pressure to the dune ecosystems development, with hazards like soil erosion, flooding and habitat loss. Proper environmental management is required to ensure the continued survival of this coastal habitat and to maintain the diversity and stability of the ecosystem on this site and accurate topographic modelling is considered a prerequisite for such management.

\section{Methodology}

This study considered three different surveying methods to gather spatial data for the Brittas-Buckroney dune system. These were LiDAR data acquired from the NMA, and two on-site data collection technologies, viz. TLS and RPAS.

\section{Data acquisition}

\section{LiDAR}

LiDAR data of the study site were available from OSi. The Lidar scanner used by OSi was an airborne Leica ALS50
Fig. 1 Morphology of the BrittasBuckroney dune complex

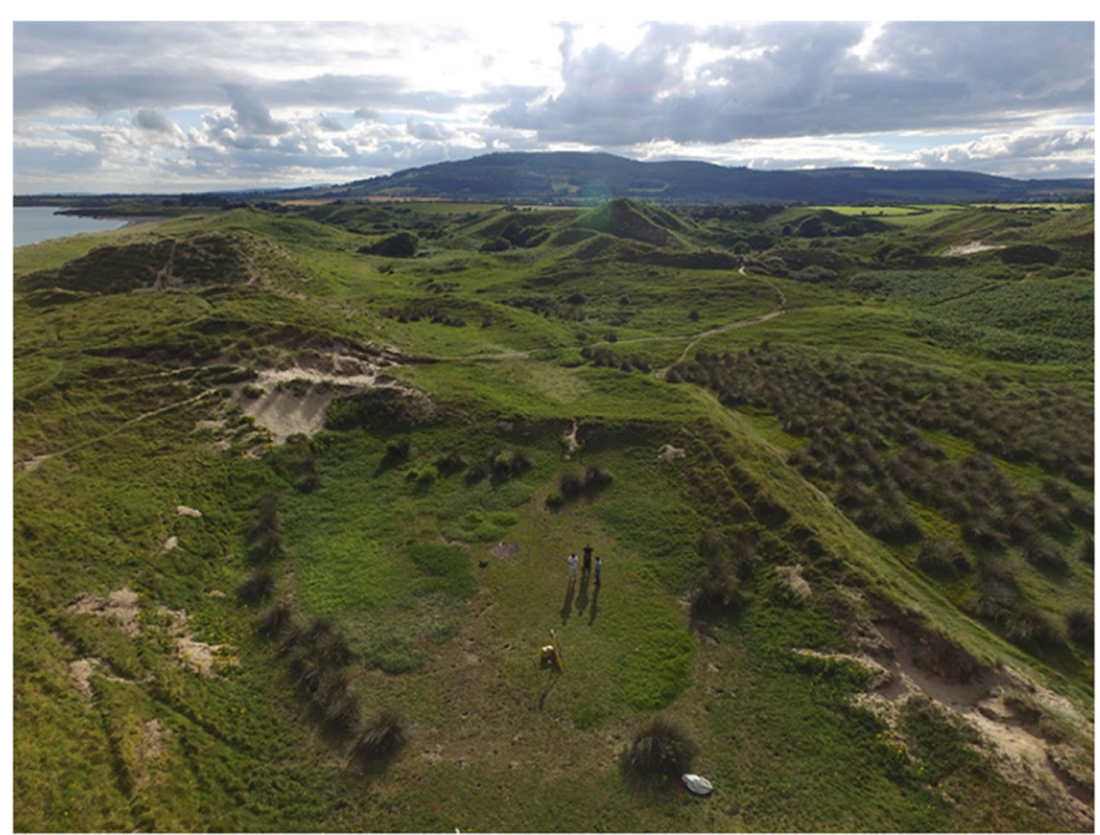




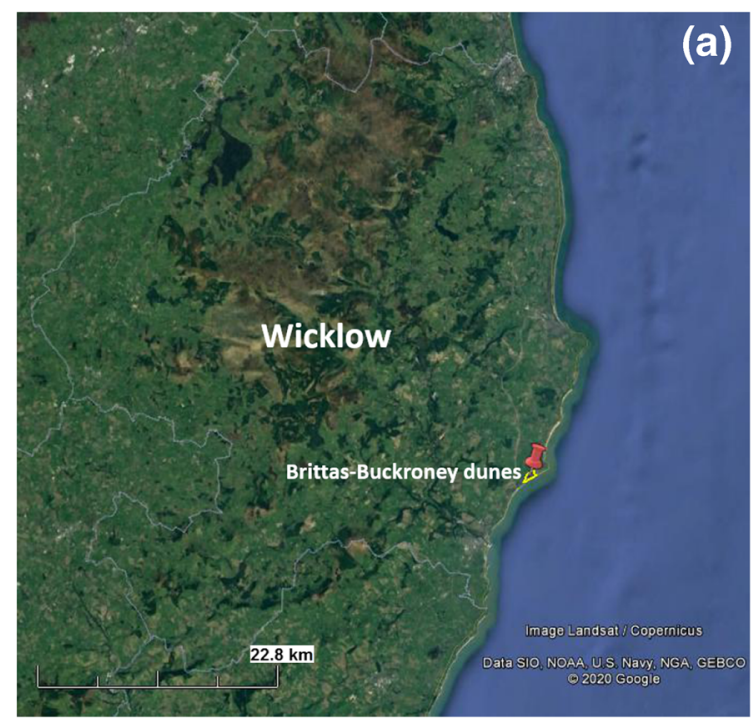

Fig. 2 Study site (a) General location and (b) Brittas-Buckroney dunes

(Ordnance Survey Ireland (OSI) 2017). This scanner emits 150,000 pulses every second creating a point cloud of millions of pixels collected in $\mathrm{X}, \mathrm{Y}, \mathrm{Z}$ (easting, northing and elevation). After capturing the raw point cloud each point is then classified into different layers, such as ground, buildings and vegetation. The final outputs are of high accuracy and provide vertical accuracies between $0.15 \mathrm{~m}$ to $0.25 \mathrm{~m}$.

In this research, the acquisition date of the dataset was 28/04/2011. The data file contained the Easting, Northing and Elevation information for each point recorded in the Irish Transverse Mercator (ITM) coordinate system. The horizontal spatial resolution of the data was $0.5 \mathrm{~m}$ and the vertical accuracy was $0.5 \mathrm{~m}$ (Ordnance Survey Ireland (OSI) 2017).

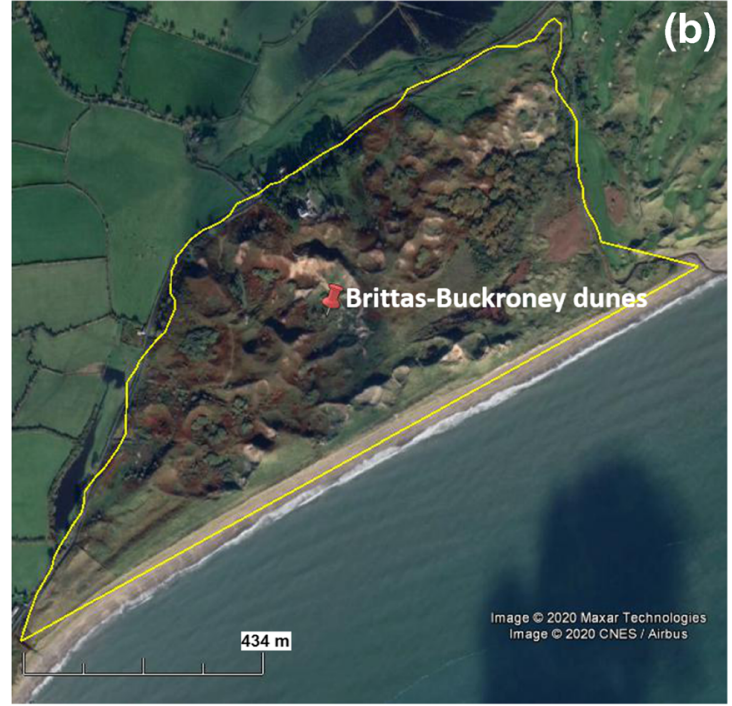

\section{TLS}

The GLS2000 captures point cloud data with the scan rate of 120,000 pulses per second with an accuracy of $3.5 \mathrm{~mm}$ up to $150 \mathrm{~m}$ distance. The scanner has a $170^{\circ}$ wide-angle camera and the scan range over $350 \mathrm{~m}$. The field view of the scanner is $360^{\circ}$ horizontally, and $320^{\circ}$ vertically. A complete $3 \mathrm{D}$ model of an object such as sand dune typically required several scans from different locations which are subsequently registered together. These scans are captured at predetermined ground control points (GCPs) to enable precise geolocation.

The coordinate positions of GCPs used in the TLS survey of the study area were measured using a Trimble 5800 GNSS receiver recording in the ITM coordinate system. The data
Fig. 3 a SenseFly eBee RPAS surveyed on-site b GCPs set on site for RPAS surveying

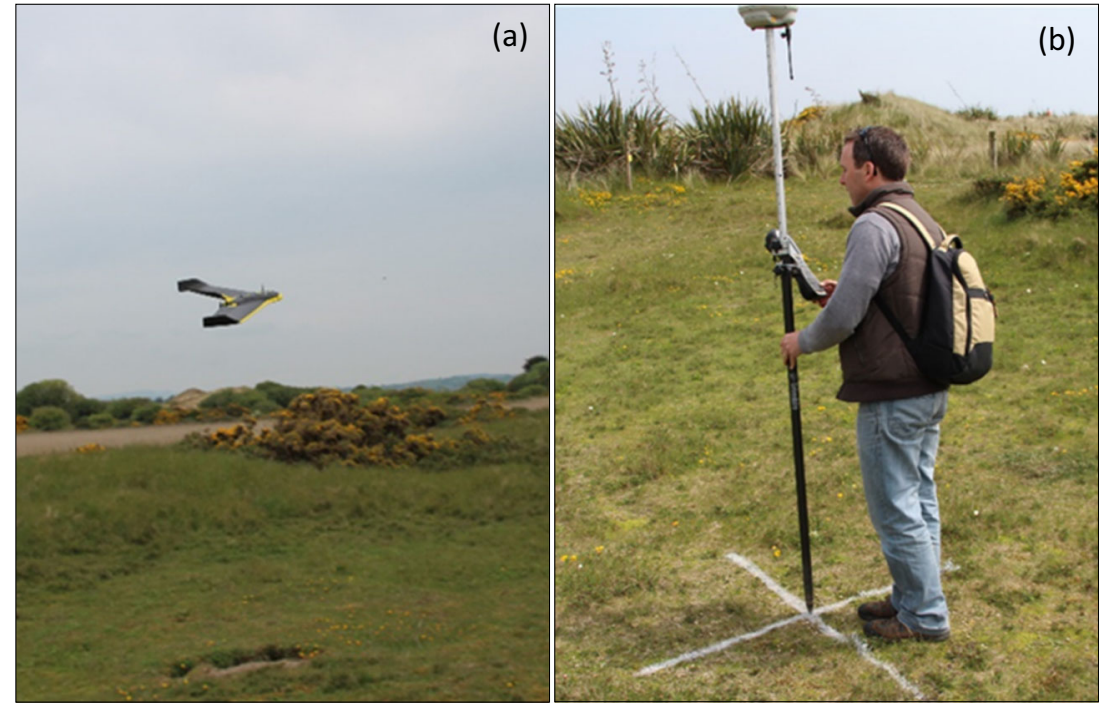


Fig. 4 The flowchart of data processing from LiDAR, TLS and RPAS technologies
LiDAR

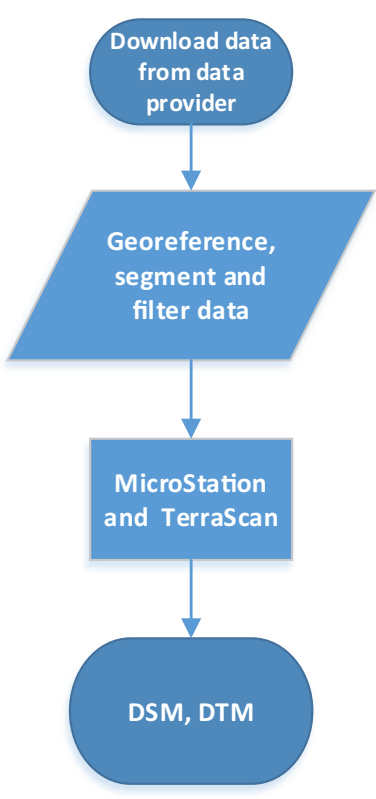

TLS

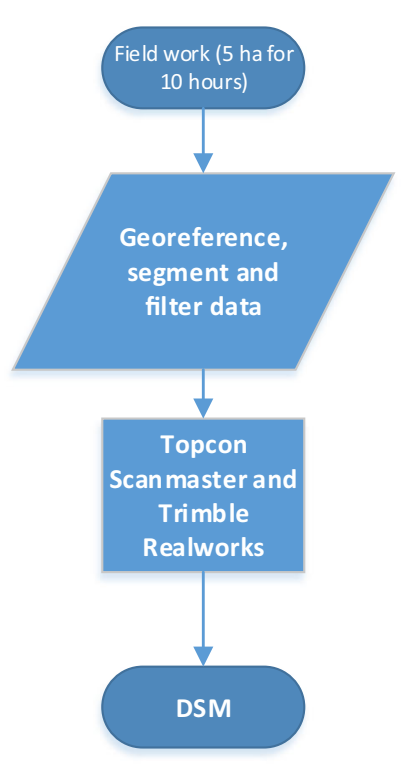

RPAS

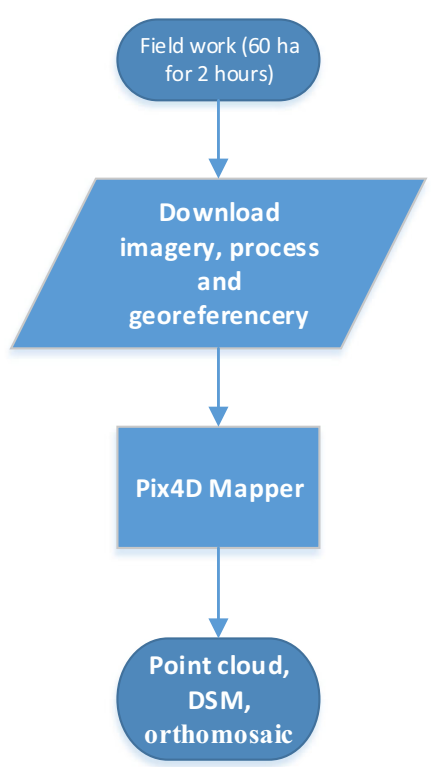

from a TLS survey is in the form of a point cloud. All points within the point cloud have $\mathrm{X}, \mathrm{Y}$, and $\mathrm{Z}$ coordinate and laser return intensity values. The points were in an XYZIRGB format, representing $\mathrm{X}, \mathrm{Y}, \mathrm{Z}$ coordinate, return intensity, and Red, Green, Blue colour values taken from the on-board digital camera.

\section{RPAS}

A SenseFly eBee RPAS (Fig. 3 (a)) was used to capture images of the study site. The SenseFly eBee RPAS can cover up to $12 \mathrm{~km}^{2}$ in a single automated mapping flight, while flights over smaller areas, at lower altitudes, can acquire images with a ground sampling distance of down to $1.5 \mathrm{~cm}$ per pixel. The resulting point cloud, with GCPs used for georeferencing, can achieve horizontal and vertical accuracy of $3 \mathrm{~cm}-5 \mathrm{~cm}$, while the resulting point cloud without GCPs has absolute horizontal and vertical accuracy of $1 \mathrm{~m}-5 \mathrm{~m}$.

Thrity-two GCPs were established around the study site to georeference the data from the RPAS. These were marked as white crosses identifiable in the images captured by the RPAS (Fig. 3 (b)). The GCPs were in the ITM coordinate system and positions were determined using a Trimble 5800 GNSS receiver connected to the Trimble VRS commercial NRTK system.

To maintain the high quality of the captured imagery, and considering the $20 \mathrm{~min}$ - $25 \mathrm{~min}$ battery life for a single flight of the RPAS, the study site was divided into three sections, North, Centre and South. Settings for each flight included $70 \%$ overlap along lines and $60 \%$ side-lap between lines, flight height of $120 \mathrm{~m}$ and flight times of c. 20 min optimizing the data capture time with respect to battery life. In the three sections, the number of images collected by the RPAS flight was 212, 209, and 149 respectively for the North, Centre and South sections.

The raw datasets from LiDAR and TLS were point clouds, whereas RPAS captured numerous overlapping images. By matching different images captured by RPAS, a point cloud

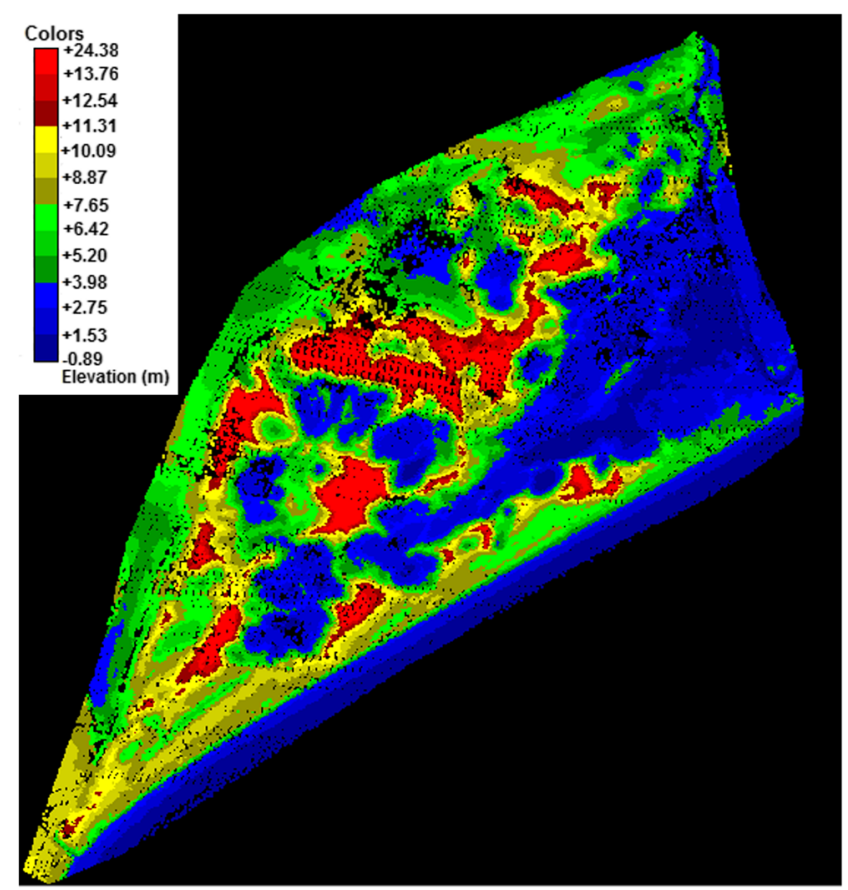

Fig. 5 Digital Surface Model (DSM) of Buckroney dune complex processed by LiDAR data

\section{Data processing}



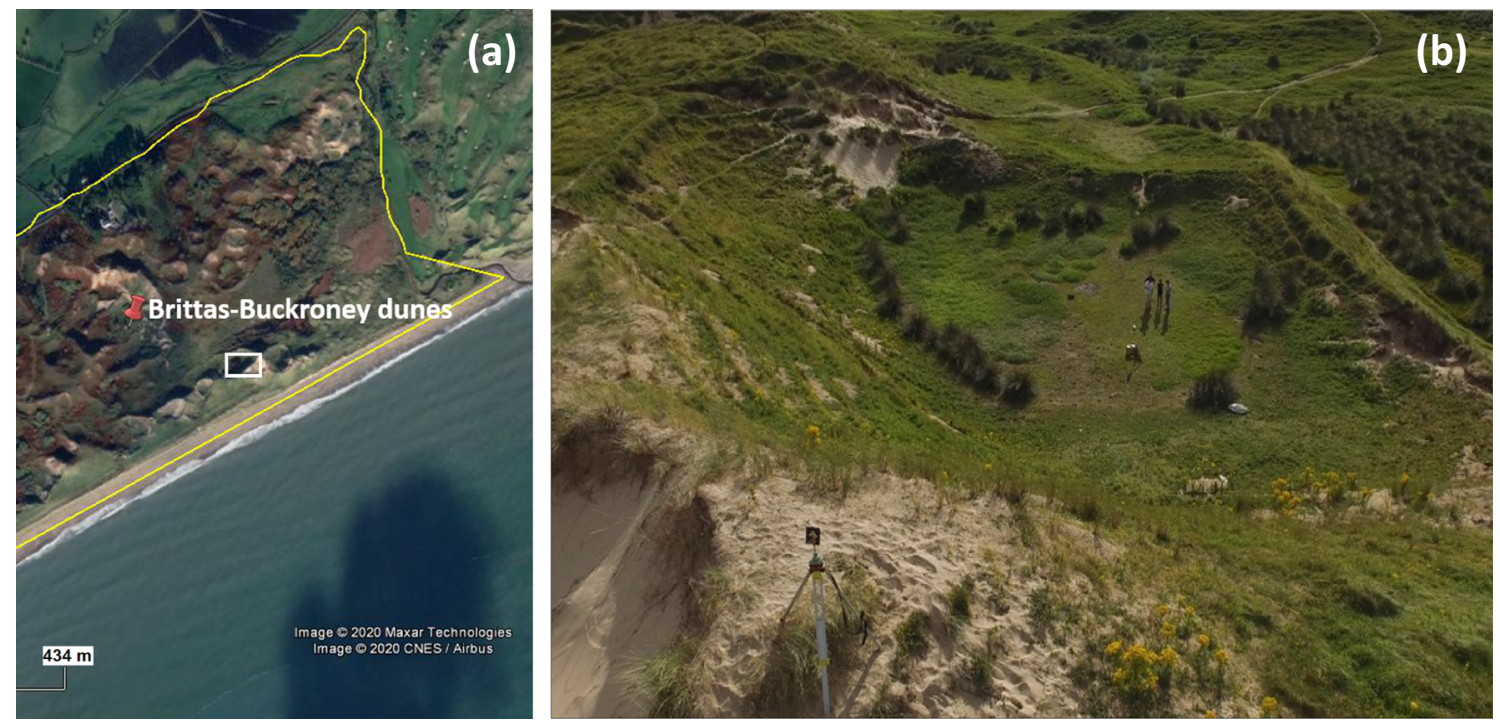

Fig. 6 Selected dune area (a) general location (b) detail imagery

of the ground surface was generated by SfM technology. Point clouds from the LiDAR, TLS and RPAS surveys then were used to generate DSMs for further study. To process the collected datasets, specific software was required in each case. Figure 4 outlines the processing steps of datasets acquired by LiDAR, TLS and RPAS.

\section{Model comparison}

DSMs were generated from the datasets collected by the three different methods, i.e. LiDAR, TLS and RPAS. Although it was not practical to create a $3 \mathrm{D}$ model for the whole study site by TLS technology, the model created from TLS data was used as reference data for an accuracy assessment of the models generated by both the LiDAR and the RPAS data. Single point accuracy based on TLS collection is $0.003 \mathrm{~m}$ (Topcon Corporation 2014). Models based on LiDAR and RPAS technology were compared with the single dune model created by TLS data via CloudCompare software. The calculated offset between the models represented the accuracy of the models created by LiDAR and RPAS.

\section{Outcomes}

The results show the topographic models of the Buckroney dune system created using the three surveying technologies, viz. LiDAR, TLS and RPAS.

\section{LiDAR}

The LiDAR data is commonly segmented by using different filters to extract the ground surface or the above-ground features. Considering the first returns of laser light, DSM (Fig. 5) and contour models of the site from LiDAR data were produced. The spatial resolution of the models was $0.2 \mathrm{~m}$. In the DSM, the colour variation from blue to red represents elevation in the range $-0.89 \mathrm{~m}-+24.39 \mathrm{~m}$.

Fig. 7 DSM of selected dune produced by TLS technology

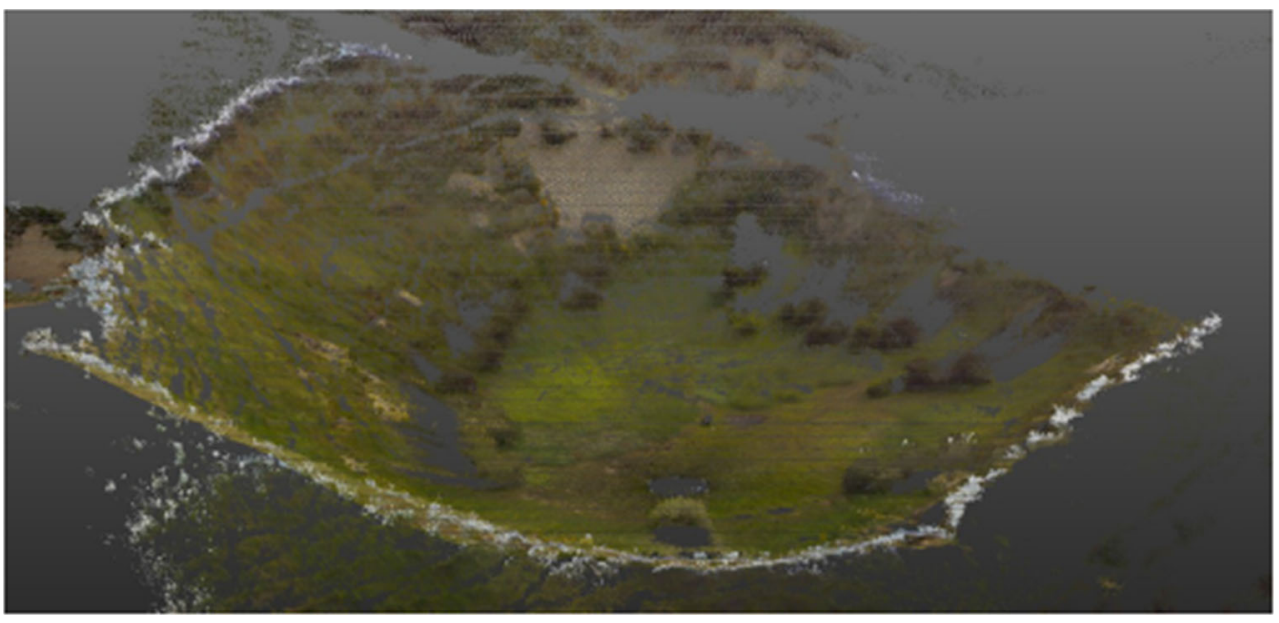


Fig. 8 Orthomosaic model of the study site with a detailed extract

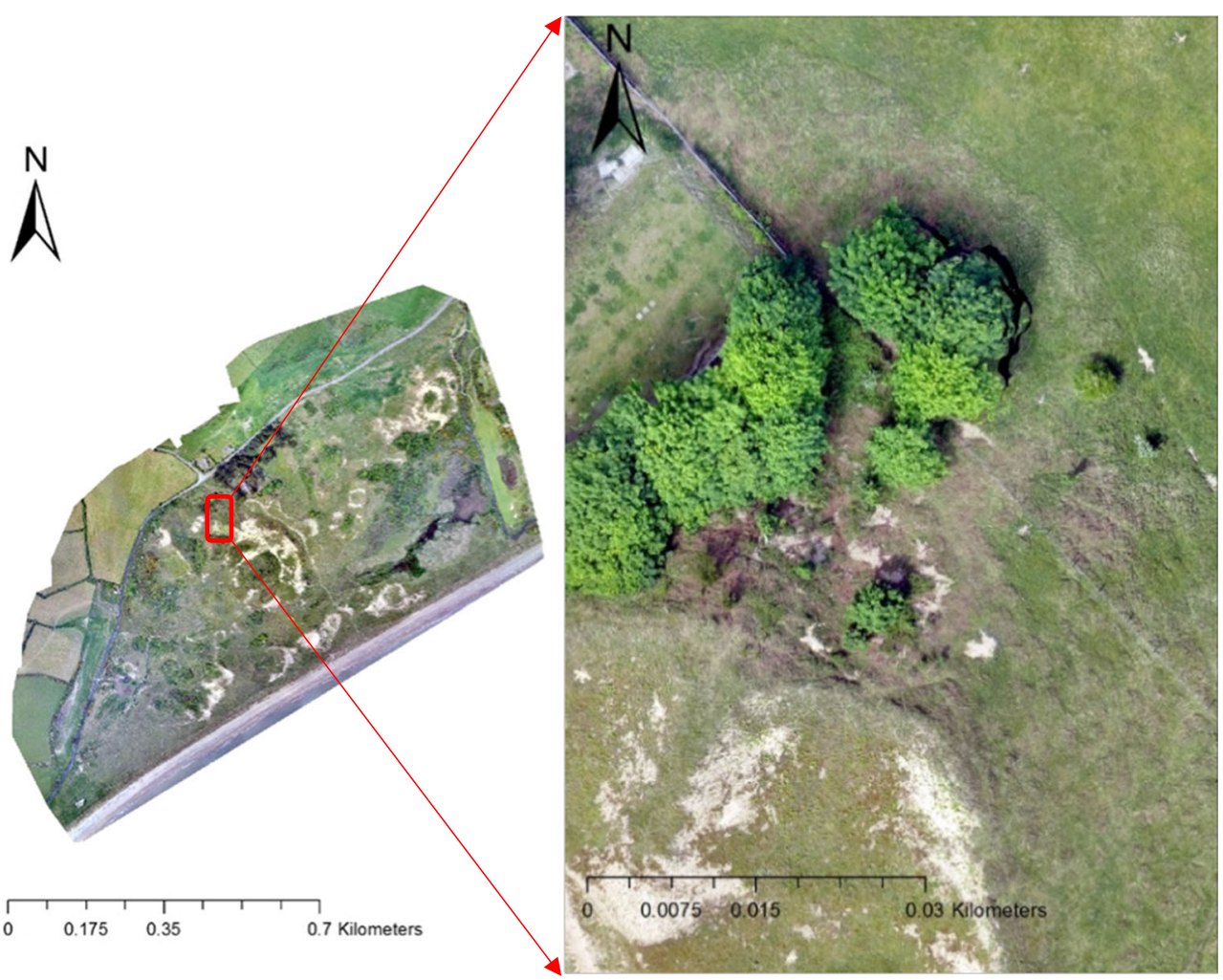

\section{Terrestrial laser scanner}

From the TLS data, a higher resolution DSM of the selected dune in the white rectangle in Fig. 6 was created. The resolution of the model was $1 \mathrm{~cm}$. This model was georeferenced to the ITM coordinate system by reference to three GCPs. TLS can collect multiple return signals from a target. The data presented in Fig. 7 used the first return signals to create the DSM.

\section{RPAS}

Using a dense image matching process, geo-referenced 3D point clouds, orthomosaics, DSMs, contour lines, and textured mesh models were generated for the study site from the RPAS imagery. These outcomes were referenced to the ITM grid coordinate system, with a spatial resolution of $0.034 \mathrm{~m}$ and a spatial accuracy of $0.035 \mathrm{~m}$ when checked against 10 GCPs.

Pix 4D software was used for the processing and a 3D point cloud of the study site was generated from the overlapping images. The orthomosaic (Fig. 8) is a mosaic image adjusted for topographic relief, lens distortion, and camera tilt so it can be used to scale true distances. This high resolution orthomosaic is a useful product suitable for land feature classification and volumetrics analysis. The DSM (Fig. 9) when combined with the position of land features, can provide the basic morphological data for environmental modelling. Environmental models can then contribute to the exploration and identification of important processes at coastal dune complexes, for example, dunes formation, structure changes to dunes and vegetation, aeolian and other environmental influences on morphology.

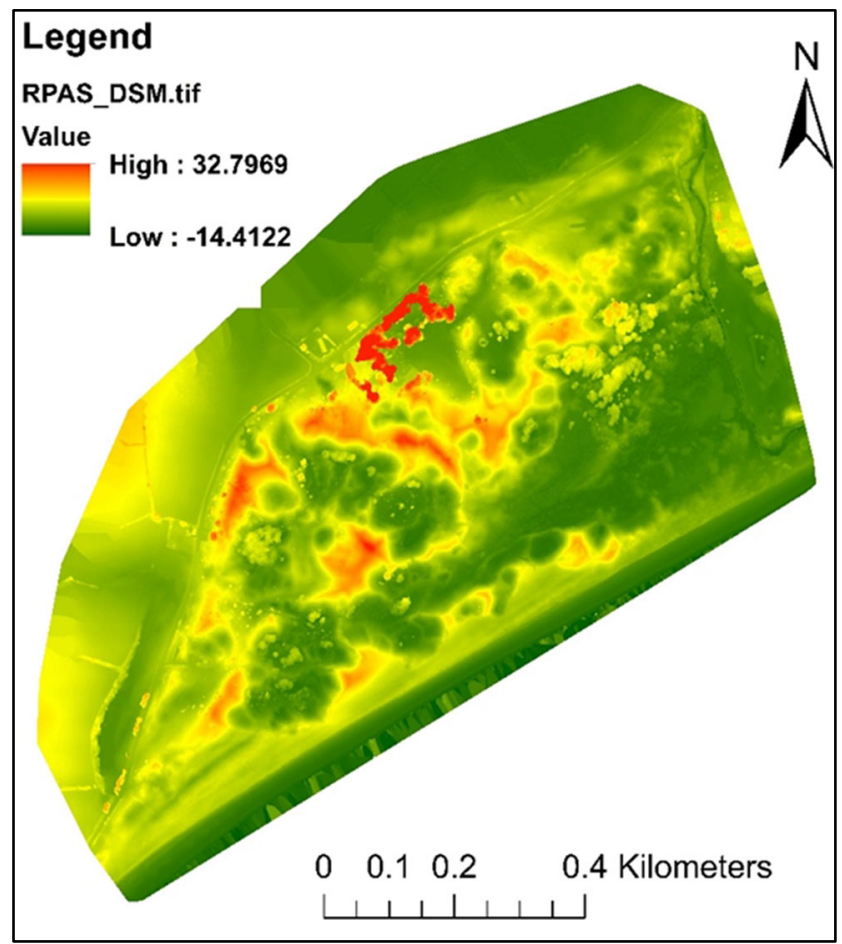

Fig. 9 DSM of study site produced from the RPAS survey 


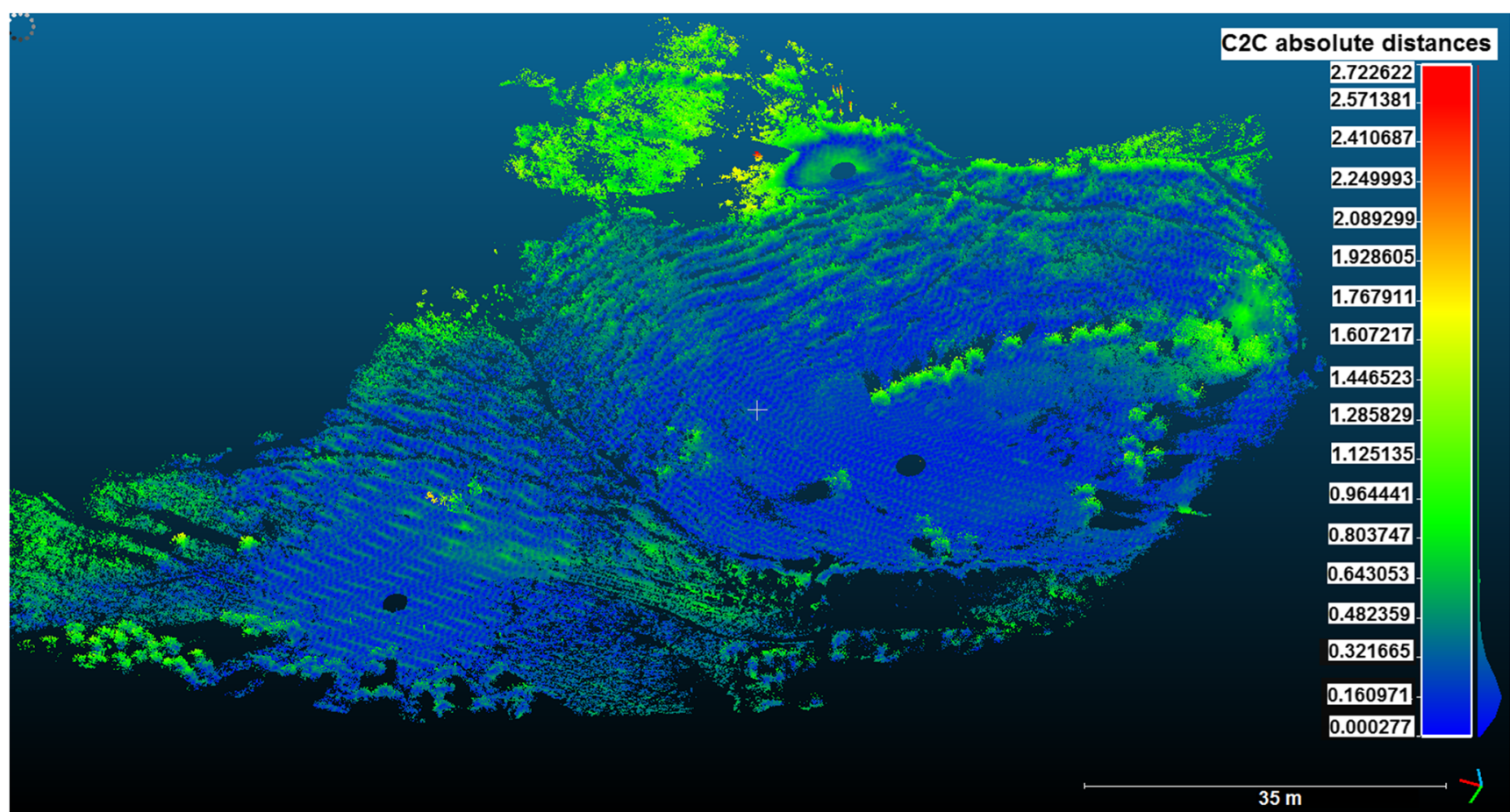

Fig. 10 Offset between the TLS model and the LiDAR model

\section{Analysis}

Based on the accuracy for a single point measurement of $0.003 \mathrm{~m}$, and allowing for a typical error budget, the estimated accuracy for the TLS model is $\pm 0.010 \mathrm{~m}$. Thus, the TLS model (Fig. 7) was used as the reference model for a comparison with the LiDAR model (Fig. 5) and the RPAS model (Fig. 9). A spatial accuracy assessment was carried out using package cloud-to-cloud separation estimation in the CloudCompare software package. The offset between TLS model and LiDAR model was $0.27 \mathrm{~m}$ and standard deviation was $0.18 \mathrm{~m}$ (Fig. 10). The offset between TLS based model and

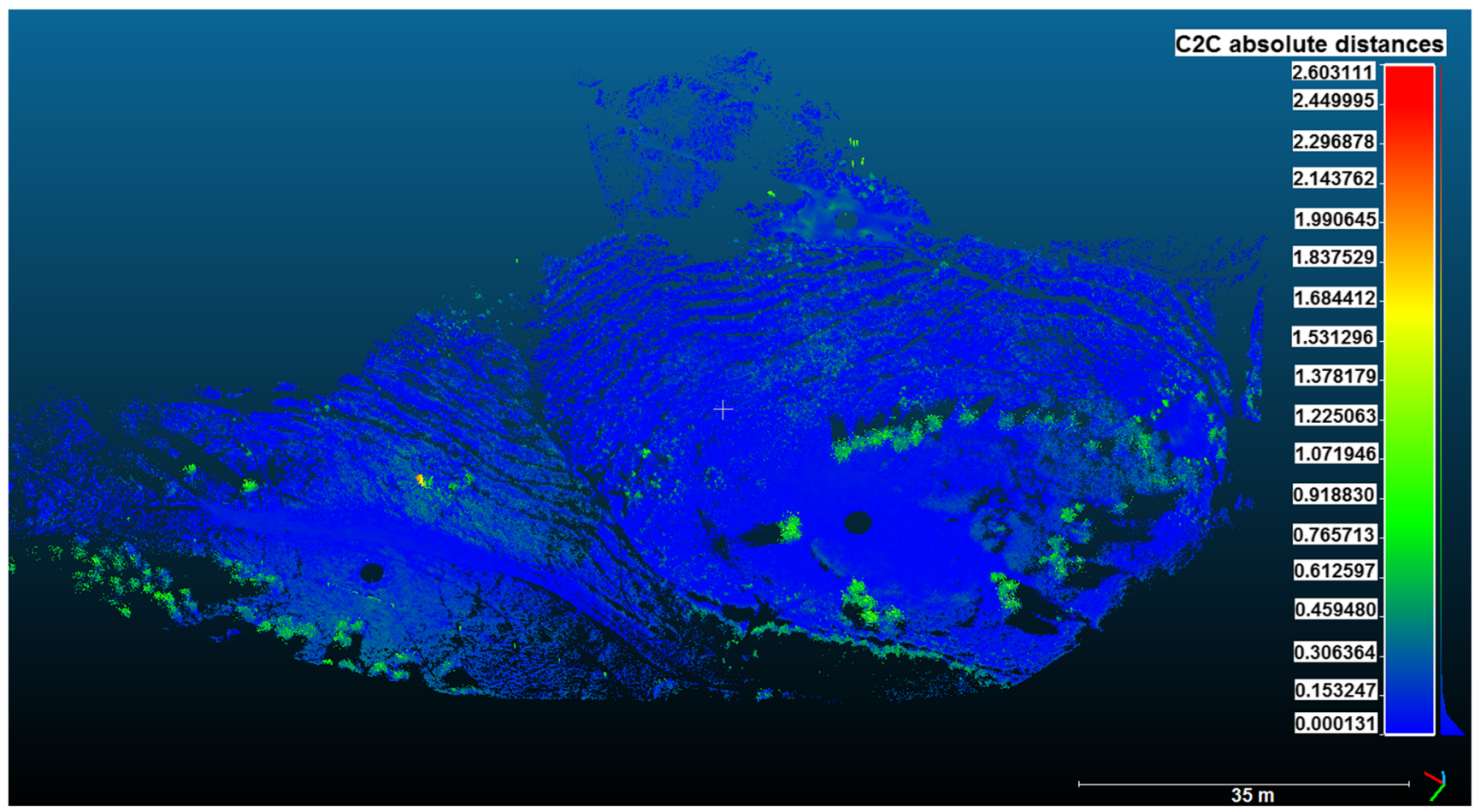

Fig. 11 Offset between the TLS model and the RPAS model 
Table 1 Comparison of LiDAR, TLS and RPAS for DSM generation of study site

\begin{tabular}{|c|c|c|c|c|}
\hline & & LiDAR & TLS & RPAS \\
\hline \multirow{7}{*}{$\begin{array}{l}\text { Data } \\
\text { acquisition }\end{array}$} & Area coverage & High & Low & Medium \\
\hline & Cost & $€ 250$ per square kilometre & About $€ 21,000$ & About $€ 10,000$ \\
\hline & Expertise level required & Competent & Proficient & Competent \\
\hline & Data collection time om-site & No field work & $\begin{array}{l}7 \mathrm{~h} \text { field work for a single } \\
\text { dune including } \\
\text { mobilisation } \\
\text { and establishment of GCPs }\end{array}$ & $\begin{array}{l}8 \mathrm{~h} \text { field work for } 60 \text { ha site } \\
\text { including mobilisation and } \\
\text { establishment of GCPs }\end{array}$ \\
\hline & Weather dependencies & Not influenced by weather change & Limited by precipitation & Limited by precipitation and wind \\
\hline & Flexibility & No flexibility & Flexibility & High flexibility \\
\hline & Collected dataset & Point cloud & Point Cloud & Georeferenced imagery \\
\hline Data processing & Software & MicroStation and TerraScan & $\begin{array}{l}\text { Topcon Scanmaster and } \\
\text { Trimble Realworks }\end{array}$ & Pix4D Mapper \\
\hline \multirow[t]{3}{*}{ Outcomes } & Outcome packages & DSM, DTM & DSM & $\begin{array}{l}\text { 3D point cloud, DSM, orthomosaic } \\
\text { image }\end{array}$ \\
\hline & Resolution & $0.2 \mathrm{~m}$ & $0.003 \mathrm{~m}$ & $0.034 \mathrm{~m}$ \\
\hline & Accuracy & $0.3 \mathrm{~m}$ & $0.010 \mathrm{~m}$ & $0.1 \mathrm{~m}$ \\
\hline
\end{tabular}

RPAS model was $0.11 \mathrm{~m}$ and standard deviation was $0.18 \mathrm{~m}$ (Fig. 11).

LiDAR, TLS and RPAS are all options for generating DSMs of a small coastal dune complex. However, the resolution, coverage and labour investment of these three methods vary. Based on this study, Table 1 compares the three methods considered for topographic models.

Based on these accuracy assessment figures (Figs. 10 and 11) and further comparison between the models (Table 1), RPAS was considered as the better choice for the topographic modelling of this 60 ha coastal dune complex for this particular study.

\section{Conclusion}

In this study, three surveying methods for data collection were explored for topographic modelling of the 60 ha Buckroney coastal dune complex in Ireland, viz. LiDAR data, TLS and RPAS. Using both existing LiDAR data and RPAS technology, it was possible to complete the high resolution topographic modelling of the site within one day. In this timescale, TLS was only capable of generating a topographic model of a single dune within the study site. However, this model was of high resolution $(0.01 \mathrm{~m})$ and high accuracy $(0.010 \mathrm{~m})$ and was used as the reference model for an accuracy assessment of the models created by LiDAR and RPAS. The results show the model based on RPAS data has higher resolution $(0.034 \mathrm{~m})$ and higher accuracy $(0.11 \mathrm{~m})$ than the model generated from the LiDAR dataset. The RPAS solution also provided more up-to-date and flexible data for modelling. Data collection using RPAS was completed in one day for a 60 ha study site which demonstrated the efficiency of the RPAS survey method in dune complex areas. As the RPAS surveyed remotely, it eased the difficulties of access through dunes areas with deep slopes and difficult vegetation.

However, notwithstanding the many benefits and advantages of RPAS technology in modelling, it still has some challenges with dune complexes surveying. RPAS is unable to create DTMs of coastal dune complexes as it lacks bareearth data in areas of dense vegetation. RPAS is also sensitive to certain environmental conditions, such as wind, precipitation, low light. Although the use of RPAS can save significant time at the on-site data collecting stage, more time is required for data processing. Preliminary items need to be take into consideration as well, such as arranging permits to fly and training under RPAS regulations from the relevant aviation authority.

Acknowledgements This work was funded by the Fiosraigh scholarship programme of the Technological University Dublin. The authors wish to acknowledge SLR Global Environmental Solution Company for providing the fixed wing drone eBee for data collection and Ronan Hogan and Ray Tighe for assistance in data collection.

\section{References}

Acosta A, Carranza ML, Izzi CF (2005) Combining land cover mapping of coastal dunes with vegetation analysis. Appl Veg Sci 8:133-138

Andrews B, Gares PA, Colby JD (2002) Techniques for GIS modelling of coastal dunes. Geomorphology 48(1-3):289-308

Bemis SP, Micklethwaite S, Turner D, James MR, Akciz S, Thiele ST, Bangash HA (2014) Ground-based and UAV-based photogrammetry: a multi-scale, high-resolution mapping tool for structural geology and paleoseismology. J Struct Geol 69:163-178 
Bolivar L, Carter W, Shrestha R (1995). Airborne laser swath mapping aids in assessing storm damage. Florida Engineering, 26-27

Casella E, Rovere A, Pedroncini A, Mucerino L, Casella M, Alberto L, Firpo M (2014) Coastal and shelf science study of wave runup using numerical models and low-altitude aerial photogrammetry : a tool for coastal management. Estuar Coast Shelf Sci 149:160-167

Clark JR (1977) Coastal environment management. Wiley, Chichester

Colomina I, Molina P (2014) Unmanned aerial systems for photogrammetry and remote sensing : a review. ISPRS J Photogramm Remote Sens 92:79-97

Crapoulet A, Héquette A, Levoy F, Bretel P (2016) Using LiDAR topographic data for identifying coastal areas of northern France vulnerable to sea-level rise. J Coast Res 75:1067-1071

Curr RHF, Koh A, Edwards E, Williams AT, Daves P (2000) Assessing anthropogenic impact on Mediterranean sand dunes from aerial digital photography. J Coast Conserv 6:15-22

D'iorio M, Jupiter SD, Cochran SA, Potts DC (2007) Optimizing remote sensing and GIS tools for mapping and managing the distribution of an invasive mangrove (Rhizophora mangle) on south Molokai, Hawaii. Mar Geod 30(1-2):125-144

Dow JM, Neilan RE, Rizos C (2009) The international GNSS service in a changing landscape of global navigation satellite systems. J Geod 83:191-198

Ersilia O, Constantin C, Marius S (2012) Terrestrial laser scanner surveying versus Total Station surveying for 3D building model generation. Mathematical Modelling in Civil Engineering 4: $168-178$

Fernández-Guisuraga JM, Sanz-Ablanedo E, Suárez-Seoane S, Calvo L (2018) Using unmanned aerial vehicles in Postfire vegetation survey campaigns through large and heterogeneous areas: opportunities and challenges. Sensors 18:E586

Gomez C, Green DR (2017) Small unmanned airborne systems to support oil and gas pipeline monitoring and mapping. Arab J Geosci 10:202

Grebby S, Cunningham D, Tansey K, Naden J (2014) The impact of vegetation on lithological mapping using airborne multispectral data: a case study for the North Troodos region, Cyprus. Remote Sens 6:10860-10887

Hodgson A, Kelly N, Peel D (2013) Unmanned aerial vehicles (UAVs) for surveying marine Fauna : a Dugong case study. PLoS One 8(11): e79556

Hutchinson MF, and Gallant JC (1999) "Representation of terrain." In geographical information systems: principles and technical issues, edited by Longley PA, Goodchild MF, Maguire DJ, and Rhind DW, 105-124, 2nd edition. New York: John Wiley \& Sons

Lee J, Park J, Choi J (2013) Evaluation of sub-aerial topographic surveying techniques using Total Station and RTK-GPS for applications in macrotidal Sand Beach environment. Journal of Coastal Research, Special Issue No 65:535-541

Li X, Zhang X, Ren X, Fritsche M, Wickert J, Schuh H (2015) Precise positioning with current multi-constellation global navigation satellite systems: GPS, GLONASS. Galileo and BeiDou Scientific Reports 5:8328

Liang S, Li X, Wang J (2012) Advanced remote sensing. Terrestrial Information Extraction and Applications, 1st Edition, Chapter 2. Academic Press

Lucas NS, Shanmugam S, Barnsley M (2002) Sub-pixel habitat mapping of a coastal dune ecosystem. Appl Geogr 22(3):253-270

MacLeod M, Pereira da Silva C, Cooper JAG (2002) A comparative study of the perception and value of beaches in rural Ireland and Portugal: implications for coastal zone management. J Coast Res 18(1):14-24

McGovern EA, Holden NM, Ward SM, Collins JF (2002) The radiometric normalization of multi-temporal thematic mapper imagery of the midlands of Ireland- a case study. Int J Remote Sens 23(4):751-766

McKenna J, MacLeod M, Cooper A, O'Hagan AM, Power J (2005) Land tenure type as an underrated legal constraint on the conservation management of coastal dunes: examples from Ireland. Area 37(3): 312-323

Mieczysław B (2013). Study of reliable rapid and Ultrarapid static GNSS surveying for determination of the coordinates of control points in obstructed conditions. Journal of surveying engineering ASCE, 188-194

National Parks \& Wildlife Service (NPWS) (2013) Site synopsis: buckroney-brittas dunes and fen SAC. NPWS site documents, 000729_Rev13.Doc.https://www.npws.ie/protected-sites/sac/ 000729

Olbert AI, Comer J, Nash S, Hartnett N (2017) High-resolution multiscale modelling of coastal flooding due to tides, storm surges and rivers inflows. A Cork City example. Coast Eng 121:278-296

Ordnance Survey Ireland (OSI), viewed at Feb (2017). Highly accurate digital terrain models (DTM) or digital surface models (DSM). OSI online document.https://www.osi.ie/wp-content/uploads/2015/05/ Lidar_prod_overview.pdf

Parrish CE, Dijkstra JA, PMO’Neil-Dunne J, Mckenna L (2016) PostSandy benthic habitat mapping using new Topobathymetric Lidar technology and object-based image classification. Journal of Coastal Research, IS 76:200-209

Rapinel S, Clement B, Magnanon S, Sellin V, Laurence H (2014) Identification and mapping of natural vegetation on a coastal site using a Worldview-2 satellite image. J Environ Manag 144:236-246

Schneider TD, Panich LM (2008) Total Station mapping: practical examples from Alta and Baja California. J Calif Gt Basin Anthropol 28(2):2327-9400

Smith MJ, Chandler J, Rose J (2009) High spatial resolution data acquisition for the geosciences: kite aerial photography. Earth Surf Process Landf 34:155-161

Staiger R (2003). Terrestrial laser scanning technology, systems and applications. 2nd FIG regional conference in Marrakech, Morocco December 2-5, 2003

Timm BC, McGarigal K (2012) Fine-scale remotely-sensed cover mapping of coastal dune and salt marsh ecosystems at Cape cod National Seashore using random forests. Remote Sens Environ 127:106-117

Tomasello F, Ducci M, Bell J (2016) Safe integration of drones into airspace. European Parliament's committee on transport and tourism (TRAN), IP/B/TRAN/IC/2016-104

Topcon Corporation (2014). GLS-2000: Compact high-speed 3D Laser scanner. P/N:7010-2152 Rev.B TF 8/14

Turner IL, Harley MD, Drummond CD (2016) UAVs for coastal surveying. Coast Eng 114:19-24

Westley K, McNeary R (2014) Assessing the impact of coastal Erosion on archaeological sites: a case study from Northern Ireland. Conservation and Management of Archectiture Sites 16(3):185-211

Woolard JW, Colby JD (2002) Spatial characterization, resolution, and volumetric change of coastal dunes using airborne LIDAR: Cape Hatteras. North Carolina, Geomorphology 48:269-287

Zelizn V (2016) Use of low-cost UAV photogrammetry to analyze the accuracy of a digital elevation model in a case study. Measurement 91:276-287

Publisher's note Springer Nature remains neutral with regard to jurisdictional claims in published maps and institutional affiliations. 